\title{
PERSON SPEECH BEHAVIOR MARKERS IN EXTREME SITUATION (ACCORDING TO SUAKHILI LITERARY SOURCE)
}

Aida R. Fattakhova ${ }^{1}$

Evgeniya A. Biyanova ${ }^{2}$

\begin{abstract}
An extreme situation implies an active influence on the psychologicalemotional state of a person, which is expressed in tension, agitation, aggression and other manifestations of temperament, deviated from the generally accepted norms of behavior. In artistic texts, the representation of a person's speech behavior in an extreme (conflict) situation is realized through the Swahili language means that mark a conflict communicative act. In this

with an exclamation point, syntactic repetitions, the use of invective vocabulary, etc.). The authors come to the conclusion that the simultaneous implementation of these markers is observed in the dicthemes of conflict communicative acts to a greater extent. The results of the research can be used for further developments in the field of linguistics, ethnic-linguistics, psycholinguistics, grammar, translation studies, etc.
\end{abstract} article, based on the material of the Swahiliazy novel "The World is Chaos" by E. Kesilahabi, an attempt is made to study the markers that reveal the speech behavior of a conflict communicative act participants. Phonetics-graphic, grammatical and lexical markers are distinguished, the most frequent of them are identified (the use of a wide range of interjections, the highlighting of a phrase

Keywords: Linguistics, conflict, speech behavior, phonetic-graphic markers, grammatical markers, lexical markers, Swahili, Euphrase Kezilahabi.

\section{Introduction}

Throughout his life, a person is in the interaction with everything that

\footnotetext{
${ }^{1}$ Kazan Federal University, Institute of International Relations, History and Oriental Studies. e-mail: gaidaf@mail.ru. Tel.: +79631208906.

${ }^{2}$ Kazan Federal University, Institute of International Relations, History and Oriental Studies. e-mail: gaidaf@mail.ru. Tel.: +79631208906.
} 
surrounds him. Becoming a participant in a variety of speech situations, he must constantly rely on certain norms that form his speech behavior. But the rules of speech behavior of an individual are dictated not only by public norms and etiquette: internal factors such as upbringing, an environment, the belonging to any nationality, as well as the external factors determining a situation nature in which speech behavior is realized are of great importance.

The linguistics of the second half of the 20th century presents homo eloquens, "a speaking person" in the focus of linguistic research, with his ideas about communicative actions, intentions, communicative environment and the principles of communication. In this regard, the problem of speech communication optimization is one of the central issues in linguistic research [1]. The study of this problem implies the analysis of the language variant choice to develop an utterance depending on a situation, a situation nature, the relations of communicants, and so on.

The verbal behavior of an individual in an extreme situation, i.e. the situation threatening health and human life or the break of activities for important problem solution is of particular importance. In an extreme situation, a person experiences a state of emotional tension (stress), which manifests itself in various forms (the violation of psychomotorics, the changes in intellectual processes and emotional background, etc.). It is possible to analyze the reaction of an individual to an extreme nature situation not only in real time, but also on the basis of fiction material. At that, the most frequent variation of an extreme situation in literature is a conflict situation. The problem of a conflict communicative interaction is explored by psycho-, social-, pragmatic linguistics, communicative linguistics, conflictology, sociology and psychology. The works by O.S. Issers [2], H.A. Belous [3], A.V. Dmitriev and V.N. Kudryavtsev [4], K. Thomas and R. Kilman [5], R. Volkem and T. Bergman [6] and a number of other researchers highlight the fundamental concepts of communicative conflictology, such as a conflict discourse, the strategies and the tactics of conflicting party verbal behavior, communicative sabotage, etc. But since the main emphasis in the works 
of these scientific paradigms is made on the semantic-pragmatic (content) side of communicative conflicts, their linguistic peculiarities are not considered in sufficient detail [7].

The linguistic features of a conflict communicative interaction are analyzed in the works by S.R. Dadyan [7], T.A. Rubtsova [8], V.S. Tretyakova [9], etc., in which the research material was the artistic texts of English and Russian literature. In this article, an attempt is made to study the linguistic features of an individual verbal behavior in an extreme situation on the basis of the swahili-lyric novel "Dunia uwanja wa fujo" (The World Is Chaos) material of the Tanzanian writer Efras Kesilahabi [10].

\section{Methodological framework}

Taking into account the nature of the presented material, general theoretical methods of research were used in the course of this study: analysis, synthesis, analogy, classification, comparison, etc.

\section{Results}

In an artistic text, the representation of the verbal behavior of heroes in an extreme (conflict) situation is realized through linguistic means, among which the lexical-semantic and grammatical are the most vivid ones marking a conflict communicative act.

In order to study these markers during the selection of a source of literature, we proceeded from a work content. Roman E. Kesilahabi "The World is Chaos" (1975), describes Tanzanian society from different perspectives, describes social and political problems; covers the whole life of the main character Tumaini, revealing his character and hero characters through the prism of conflict situations in which they are described. A particular attention is paid to the issue of a woman status in society, the problems of raising children; cultural "backwardness" of a village are contrasted with the vices of a city, which include crime, prostitution, etc. One of the significant milestones of the novel is the signing of the Arusha Declaration, which legitimized the concept of socialism - ujamaa. The result of a political decision, is that people are faced with the problems of a very different nature.

During the analysis of Kezilahabi's novel, we identified the 
following markers, revealing the verbal behavior of the characters in an extreme situation.

1. Phonetic-graphic markers are represented by exclamation marks, interjections and font highlighting.

1.1 The most frequent markers for a conflict expression are exclamation marks that convey an emotional tension, a strong sense of excitement, emotions, discontent, etc. For example: Dennis umeniumiza! Huwezi kuniacha hivi! "Dennis, you hurt me!" You can't leave me like this!

The Swahili language literature also uses an exclamation markin sentences denoting a questionexclamation, as a rule, to convey some indignation and dissatisfaction: Kwa nini hukuniambia zamani! "Why did not you tell me that before?" During the provision of such proposals, for example, in Russian, an exclamation mark is combined with a question mark and is placed in the second place according to the rules of Russian punctuation. Unasema nini! - What are you saying?!

1.2 Interjections play a special role to express an emotional state of a speaker, his feelings and his state of mind in conflict communicative acts. In Swahili, due to numerous ethnic-cultural features, a wide range of interjections is presented that performs an expressive or a stimulating function. Interjections in Swahili in coherent speech act as individual sounds and are expressed with exclamation marks for the most part: "Mm! Sema sasa! Mm! Sema!" - Mm! Speak now! Mm! Speak! The interjection $\mathrm{mm}$ used in this example demonstrates the speaker's impatience, an intentional desire to provoke a quick response from a communication partner. In the following example, the interjection a, deriving from emotional exclamations on physical impact or immediate danger, conveys a speaker's fear and his warning about the threat: A! A! Linakula! - A! A! He will eat it! The text demonstrates the cases when in order to demonstrate the length of an exclamation sound, an interjection is graphically depicted by numerous repetitions of a final vowel sound. For example: "Smith!" "Ziiiiiii" "Kaburu" "Oh, yeah" - Smith! Heeeeey! Racist! Yeah! As a rule, this method is used by the author to convey an emotional state of people. In this case, the indignation 
and the dissatisfaction with the existing state of things is conveyed.

1.3 Font highlighting is not so common: Lakini John ... John ... basi. "But John ... John ... that's all." In this example, italics demonstrate the strong emotional tension of the speaker.

In a swahili text, English phrases can be stressed by italics. For example: "Tumaini, You are too pessimistic about life," Dennis alimalizia kwa Kiingereza. "And you are too optimistic." Tumaini alidakia. In the presented example (the phrases the author has selected in italics, are indicated in bold here. - ed.) the heroes end a tense dispute using the phrases in a foreign language. Both characters are educated, well-read, understand foreign literature, speak English, which is a sign of intelligence. In this example, the appeal of heroes to English language demonstrates their desire to be more persuasive in their position.

The font highlighting can also be represented by the division of the word into syllables or agglutinative morphemes using a hyphen or exclamation marks: We-we! Ni-ku-sikie te-na! - You! If I hear you again! Another example: Nita! Nitaku! Kuua!
"I'll kill you" Swah. In this example, the author conveys the highest degree of verbal aggression. If this communication took place in real time, the abovementioned phrases would be pronounced with an extreme indignation, excitement, special intonation, an intermittent of breathing and the violation of speech tempo.

2. Grammatical markers are one of the most common means representing the expression of an emotional state of partners interacting in a conflict situation. In this article we will analyze some of them, namely:

2.1 Negative structures. The means of negation expression in different languages differ by their variety and the presence of specific indicators. For example, different temporal and modal forms of a verb may have different negative indices; there are various indicators of a name denial, etc. [11].

Negative structures give an expressive shade, categorical and deliberate rejection of a partner's opinion. For the most part, these structures represent the requirements of a desired result, an accusation, a contempt, a disgust, etc. In Swahili, 
among the means of negation expression the most frequent are the following ones:

- the attachment of the formant ha- to the affirmative form of the verb wa na "to have". When this formant is joined to the adverbial subjective indicators of singular, in particular, the second person, a cohesive form hu (ha- + $\mathrm{u}-)$ is formed, for example: Huna akili! Huna akili! - (literally, I am crazy). You're crazy! Crazy!

- the formation of a negative form of an optative with the help of the negative formant -si, occupying the position behind the subjective indicator: Usipige kelele! - Do not shout!

2.2 Incentive proposals expressing an order, a threat, a call for joint action, a request, a protest, etc. Swahili has several types of grammatical constructions to express the significance of motivation. In the novel studied by us, the most frequent grammatical means of motivation formulation is the predicate in the form of an imperative and an optative in combination with an incentive intonation. For example:

- a predicate in imperative form:

Piga! Piga! Ua! - Beat it! Beat it! Kill it! - an optative: Baba nihurumie! "Father, have pity on me!"
Msiue! Msiue! - Dont kill! Dont kill! and etc.

The predicates in the imperative form give the utterance a hint of sharpness and categoricity, the predicates in optative, on the contrary, soften the sharpness and categoricity and acquire a shade of request.

2.3 The repetitions of syntactic constructions. Depending on a structure, the positions of the repeating elements are differed by different classifications of the repetition patterns. In conflict communicative acts, repetitions convey an emotionally-excited state of a speaker, an extreme degree of his emotion and tension. In the novel, the repetitions of successive identical members of sentences, phrases and whole sentences were distributed. For example:

Kipofu! Kipofu! Washa taa uone vizuri! - [You] are blind! Blind! Light a light bulb, maybe you'll see better!

Bwana wangu pia ana sifa! Njoo hapa! Njoo hapa tuone! - My husband also has something to brag about! Come here! Come here, let's see.

2.4 In the conditions of an extreme situation, a conflict interaction 
of communication participants is characterized by the use of incomplete sentences as the sentences, in which the member of a sentence, necessary for this sentence meaning completeness. At the peak of the emotional tension, according to the syntactic structure of phrases, a speaker's speech is simplified and characterized by an abruptness. The missed members of a sentence are restored by communicative act participants from a situation knowledge, from a previous context.

As an example, we analyze an episode with the robbery of Tumaini's house: Funguo za sanduku hili! Upesi! "The keys to this chest Fast!"

Mara ya mwisho upesi! Kabla sijafyatua! - "(I say) For the last time, quickly! Or I'll fire!

In the abovementioned example, the omitted predicate "say" is easily restored in the context of the presented situation.

3. Lexical markers are represented by non-normative (invective) vocabulary, as well as by the lexical units that convey a non-verbal expression of emotions.

3.1 Invective vocabulary includes the words and expressions whose function is to offend, to humiliate, to defame, to disgrace an addressee of speech or a third person and do all this in the coarsest and cynical manner. There is an abusive non-literary, obscene (derogatory), literary, but non-normative vocabulary in the novel. Let's give an example:

Malaya wewe! Toka! Hapa! Prostitute! Get out!

Mtoto wa mbwa! - Son of a bitch!

The use of invective vocabulary is conditioned by an extreme degree of emotional tension of a speaker, an acute form of aggression towards an addressee.

3.2 A verbal expression or a communicative act participant speech is accompanied by an external manifestations of emotions in an extreme situation, by which "emotional kinetics" is meant according to V.I. Shakhovsky (the mimicry and the pantomime of heroes, i.e. non-verbal expression of emotions - so far, gestures and movements) [12]. External manifestations of emotions are revealed through the author's descriptions of the emotional state of characters. For example: Tumaini alilia. Alijitetea. Machozi yalimtoka. - Tumaini cried out. 
He tried to defend himself. Tears gushed from his eyes.

An emotional kinetics also includes the examples of physical aggression expression during a conflict communicative act:

- Naye kwa hasira aliamka akampiga Mama Bahati makofi mawili hali akasema "Umezidi kiasa sasa!" And he rose in anger, slapped his mother Bakhati twice and said: "You have crossed all limits."

During the analysis of participant speech behavior markers in a conflict communicative act, the most frequent ones are revealed: the use of a wide range of interjections, the singling out of a phrase with an exclamation point, syntactic repetitions, and the use of invective vocabulary. At the same time, it should be noted that the simultaneous implementation of these markers is observed in the dicthemes of conflict communicative acts to a greater extent.

\section{Discussion}

A conflict communicative interaction is the object of research in communicative linguistics, psycho-, social-, ethnic- and pragmalinguistics, communicative linguistics, conflictology, sociology and psychology (the works by O.S. Issers, N.A. Belous, K. Thomas and R. Kilman, R. Volkem and T. Bergman, etc.), are analyzed in the study of language means that mark a conflict communicative act (the studies by S.R. Dadyyan, T.A. Rubtsova, V.S. Tretyakova, and others). A lot work has been done to highlight the fundamental concepts of communicative conflictology.

Speaking about the relevance of the topic, it should be noted that unlike the study of conflict expression language means in the literary texts of English and Russian literature, the problem of a conflict communicative act marker study on the material of East Africa literature was not covered fully. This study contributes to the study of speech behavior representation in an extreme situation of the East African region residents.

\section{Conclusions}

1. An extreme situation implies an active influence on the psychoemotional state of a person. A conflict is 
one of the most common extreme situations. An emotional background of a person in a conflict situation is reflected in verbal and non-verbal reactions. In artistic texts, the representation of verbal and non-verbal reactions of characters is carried out by the means of language that mark a conflict communicative act.

2. Using the material of the novel "The World is Chaos" of the Tanzanian writer E. Kesilahabi, the phonetic-graphic, the grammatical and the lexical markers were revealed, demonstrating the speech behavior of a conflict communicative act participants. The most frequent of them are the following ones: the use of a wide range of interjections, the singling out of a phrase with an exclamation point, syntactic repetitions, the use of invective vocabulary. The analysis of these markers implementation indicates that in most cases these markers are used simultaneously during an emotional background transfer of work characters.

\section{Summary}

The study of verbal behavior in AN extreme situation of East African literature characters through the language means marking a conflict communicative act helps to identify the expressive means used by the author to develop the communicative strategy of the characters, and also promotes the understanding of representative psychological characteristics of various ethnic and linguistic groups inhabiting East Africa.

\section{Acknowledgements}

The work is performed according to the Russian Government Program of Competitive Growth of Kazan Federal University.

\section{References}

Vorontsova T.A. Speech aggression: invasion in the communicative space. Izhevsk: Publishing house "Udmurt University". p. 252, 2006.

Issers O.S. Speech influence: a textbook. - Moscow: Flint. p. 224, 2011.

Belous N.A. Structural and semantic aspects of conflict discourse in communicative space. - M: FL of the 
Russian Academy of Sciences: ULGU.

p. $224,2007$.

Tretyakova $\quad$ V.S. Speech

communication: harmony and conflict. -

Dmitriev A.V., Kudryavtsev V.N. Ekaterinburg: Publishing house of Introduction to the general theory of RGPPU. p. 231, 2009.

conflict. - M. MAEP publishing house, Kalita, p. 157, 1998.

Kezilahabi. E. Dunia uwanja wa fujo. Nairobi: Vide-Muwa Publishers. p. 132,

Thomas, K. W., \& Kilmann, R. H. 2007.

Thomas-Kilmann Conflict Mode Instrument. Mountain View, CA: Xicom, a subsidiary of CPP, Inc. 1974.

Miestamo, M. An Overview of Typological Research. - Language and linguistic compass. 1/5. pp. 552-570,

Volkema, R. J., \& Bergmann, T. J. 2007.

Conflict styles as indicators of behavioral patterns in interpersonal conflicts. Journal of Social Psychology, 135 (1), pp. 5-15, 1995.

Shakhovsky V.I. Linguistic theory of emotions. - Moscow: Gnosis. p. 416, 2008

Dadyan S.R. Conflict dialogue in the work of art. Abstract from the dis. of Phil. Cand. - Rostov-on-Don. p. 24, 2011.

Rubtsova A.S. Speech behavior of a person in an extreme situation (on the basis of English-language fiction). Bulletin of the Moscow State Humanitarian University named after M.A. Sholokhov. Series: Philol. - №2. pp. 64-69, 2012. 